\title{
Clinical and endoscopic features of aorto-duodenal fistula resulting in its definitive diagnosis: an observational study
}

\author{
Chikamasa Ichita ${ }^{1 *} \mathbb{D}$, Akiko Sasaki ${ }^{1}$, Chihiro Sumida ${ }^{1}$, Karen Kimura' ${ }^{1}$ Takashi Nishino ${ }^{1}$, Junichi Tasaki ${ }^{1}$, \\ Sakue Masuda ${ }^{1}$, Kazuya Koizumi ${ }^{1}$, Jun Kawachi ${ }^{2}$ and Makoto Kako'
}

\begin{abstract}
Background: Upper gastrointestinal (Gl) bleeding is the most important presentation of an aorto-duodenal fistula (ADF). Early diagnosis is difficult, and the disease is associated with high mortality. The present study aimed to examine the clinical and the endoscopic characteristics of ADF in eight patients who presented to our hospital. We also sought to clarify the diagnostic approach towards the disease.
\end{abstract}

Methods: The present study examined the clinical and the endoscopic/computed tomography (CT) characteristics of ADF in eight patients who were definitively diagnosed with this condition in a 12-year period at our hospital.

Results: The patients comprised of five men and three women, with a mean age of 69.8 years. Upper gastrointestinal bleeding was the chief complaint for all the patients. Out of these, two patients presented with shock. The patients' mean haemoglobin at presentation was $7.09 \mathrm{~g} / \mathrm{dL}$, and the mean number of blood transfusions was 7.5. All patients had undergone intervention to manage an aortic pathology in the past. As the first investigation, an upper GI endoscopy in 5 and a CT scan in 3 patients were performed. In cases where CT scan was performed first, no definitive diagnosis was obtained, and the diagnosis was confirmed by performing an upper Gl endoscopy. In cases where endoscopy was performed first, definitive diagnosis was made in only one case, and the other cases were confirmed by the CT scan. In some cases, tip attachments, converting to long endoscopes, and marking clips were found useful.

Conclusions: In patients who have undergone intervention to manage an aortic pathology and have episodes of upper gastrointestinal bleeding, ADF cannot be definitively diagnosed with only one investigation. In addition, when performing upper Gl endoscopy in cases where an ADF is suspected, tip attachment, converting to a long endoscope, and using marking clips can be helpful.

Keywords: Aorto-duodenal fistula, Aorto-enteric fistula, Upper gastrointestinal bleeding

\section{Background}

Aorto-duodenal fistula (ADF) is found in $0.05-0.07 \%$ of autopsies and is, therefore, considered rare [1]. It is difficult to diagnose early and is associated with high mortality [2]. Few case reports of ADF have been published,

\footnotetext{
*Correspondence: ichikamasa@yahoo.co.jp

1 Gastroenterology Medicine Center, Shonankamakura General Hospital,

1370-1 Okamoto, Kamakura, Kanagawa 247-8533, Japan

Full list of author information is available at the end of the article
}

although some studies have summarised multiple cases [1-17]. Our institution is an emergency hospital that was able to accommodate at least 14,000 emergency transports and at least 43,000 emergency consultations in 2019. As such, a relatively high number of cases of ADF have been treated in our institution. The present study aimed to examine the clinical and endoscopic characteristics of $\mathrm{ADF}$ in eight patients at our hospital. It also sought to clarify how the disease can be diagnosed appropriately. 


\section{Methods}

Eight patients were diagnosed with ADF at our institution between April 2009 and April 2020. The present study examined the baseline, clinical and laboratory data, past medical history, endoscopic and computed tomograohy (CT) scan findings, number of blood transfusions received, definitive treatment, and outcomes. The type of scope used during endoscopy, the use of tip attachments, and marking clips were also recorded. Shock was defined as systolic blood pressure below $60 \mathrm{mmHg}$. An increase in body temperature $\left(>38{ }^{\circ} \mathrm{C}\right)$, white blood cell (WBC) count, and C-reactive protein (CRP) level indicated the possibility of infection. We first performed endoscopy using GIF-Q260J (Olympus, Tokyo, Japan). However, when no obvious bleeding was found and bleeding from the deep duodenum (such as patients with a history of aortic pathology) was suspected, a detailed examination of the duodenum was performed using a tip attachment. When no abnormalities were found with using a tip attachment, we switched to a paediatric colonoscope PCF-PQ260L (Olympus, Tokyo, Japan) and searched for bleeding in the deep duodenum.

In this study, the diagnosis of ADF was made following the recommendations of a previous report [2-4, 6-11]. Endoscopic findings confirmed ADF when endoscopy showed an exposed aortic stent in the duodenum. In addition, ADF was suspected when pulsatile lesions (erosions, protuberances, or blood clots) were found in the duodenum without any other bleeding source, or when a massive amount of fresh blood from an unknown origin was observed in the duodenum [3-6]. For the CT findings, ADF was confirmed when CT showed extravascular leakage from the aorta to the duodenum. In addition, ADF was suspected when the aorta and the duodenum were adjacent to each other, ectopic air in the aorta or a saccular aneurysm of the aorta adjacent to the duodenum was present $[2,4,7-11]$. If ADF was suspected after one investigation, the other was performed. The findings of both the investigations were corroborated with each other to confirm the diagnosis. Surgery was promptly performed when the diagnosis was confirmed. In the case of upper gastrointestinal bleeding, our hospital's protocol prioritises performing an upper GI endoscopy over a CT scan. CT examination was performed first only when there was a history of a recent endoscopy and when CT was more easily accessible.

\section{Results}

The characteristics of patients with ADF are shown in Tables 1,2, and 3. The patients comprised five men and three women, with a mean age of 69.8 years. Their chief complaints were haematemesis (three patients), dark stools (five patients), shock (two patients), syncope (one patient), and weakness (one patient). Of the six patients who presented with no signs of shock, two developed shock during endoscopy. One of them died as a result of uncontrolled bleeding during endoscopy. The mean haemoglobin level at presentation was $7.09 \mathrm{~g} / \mathrm{dL}$, and the mean number of blood transfusions was 7.5. All patients had undergone intervention to manage aortic pathology ( 7 months to 13 years prior): four underwent aortic stent implantation to manage an abdominal aortic aneurysm, three had vascular prosthesis replacement, and one underwent para-aortic radiation because of lymph node metastasis secondary to cervical cancer.

The ADF diagnostic procedure is shown in Fig. 1. As the first investigation, upper GI endoscopy was performed on five patients and CT was performed on three patients. When CT was performed first, the aorta and the duodenum were adjacent to each other in all 3 cases (case 1, 7 and 8), and ectopic air was observed in the aorta adjacent to the duodenum in one case (Fig. 2, case 2). However, none of them showed findings of extravascular leakage into the duodenum from the aorta, which is required for the definitive diagnosis of ADF. Therefore, an upper GI endoscopy was performed. Pulsatile protuberances were observed in two patients (cases 1 and 7) (Fig. 3, case 1), and massive fresh bleeding from an unknown origin was found in the duodenum in one case (Fig. 4, case 8). Of the five patients who underwent upper GI endoscopy first, stent exposure was present in only one case, and thus, the definitive diagnosis of ADF was made (Fig. 5, case 2). The other four patients had findings suspicious for ADF. One had a pulsatile protuberance (Fig. 6, case 6), one presented with a pulsatile blood clot (Fig. 7, case 5), and two had massive fresh bleeding from an unknown origin in the duodenum (cases 3 and 4) (Fig. 8, case 4). In these cases, CT was performed after endoscopy. CT showed that the aorta and the duodenum were adjacent in all of these cases; extravascular leakage from the aorta to the duodenum was observed in one case (Fig. 9, case 5), ectopic air in the aorta adjacent to the duodenum occurred in two cases (cases 3 and 5), and a cystic aneurysm in the aorta adjacent to the duodenum was found in two cases (cases 4 and 6) (Fig. 10, case 6). One patient died during endoscopy (case 4), and the diagnosis was confirmed by additional post-mortem imaging. In all these patients, ADF was diagnosed based on both the endoscopic and the CT findings, and the patients were then transferred for surgical treatment. We were able to save the lives of all those patients who underwent surgery.

The fistula site was the horizontal duodenum in seven cases and the descending duodenum in one case. The types of scope used during the diagnosis were GIF-Q260J (Olympus, Tokyo, Japan) in six cases and PCF-PQ260L 
Table 1 Demographic and clinical data of eight patients

\begin{tabular}{|c|c|}
\hline \multicolumn{2}{|l|}{ April 2009 to April $2020: \mathrm{n}=8$ patients } \\
\hline Age & 69.8 years ( $41-76$ years) \\
\hline Sex & 5 males, 3 females \\
\hline Chief complaint & Hematemesis: 3 Black stool: 5 Shock: 2 Syncope: 1 Weakness: 1 \\
\hline Shock at presentation & $2(25 \%)$ \\
\hline Mean hemoglobin at presentation & $7.09 \mathrm{~g} / \mathrm{dL}(5.6-9.4 \mathrm{~g} / \mathrm{dL})$ \\
\hline Mean no. of blood transfusions & $7.5(4-14)$ \\
\hline History of treatment for any aortic pathology & $8(100 \%)$ \\
\hline \multicolumn{2}{|l|}{ Abdominal aortic aneurysm } \\
\hline After stent placement & $4(50 \%)$ \\
\hline After artificial blood vessel replacement & $3(37.5 \%)$ \\
\hline After periaortic irradiation & $1(12.5 \%)$ \\
\hline \multicolumn{2}{|l|}{ Endoscopic findings } \\
\hline Stent exposed & $1(12.5 \%)$ \\
\hline Pulsatile lesions (erosion, granulation, blood clots) & $4(50 \%)$ \\
\hline Massive fresh bleeding of unknown origin in the duodenum identified & $3(37.5 \%)$ \\
\hline Patients undergoing CT scan before endoscopy & 3 patients \\
\hline \multicolumn{2}{|l|}{ CT findings } \\
\hline Aorta and duodenum adjacent to each other & $3 / 3(100 \%)$ \\
\hline Air in the aorta adjacent to the duodenum & $2 / 3(66.7 \%)$ \\
\hline Patients undergoing CT scan after endoscopy & 4 patients \\
\hline \multicolumn{2}{|l|}{ CT findings } \\
\hline Aorta and duodenum adjacent to each other & $3 / 3(100 \%)$ \\
\hline Extravascular leakage from the aorta to the duodenum & $2 / 3(66.7 \%)$ \\
\hline Ectopic air in the aorta adjacent to the duodenum & 4 patients \\
\hline Saccular aneurysm adjacent to the duodenum & $3 / 3(100 \%)$ \\
\hline Fistula site & Horizontal part: 7 Descending part: 1 \\
\hline Type of endoscope used in diagnosis & GIF-Q260J: 6 PCF-PQ260L: 2 \\
\hline Possible surgical treatment & $7(87.5 \%)$ \\
\hline Outcome & $\begin{array}{l}\text { Death during endoscopy: } 1 \text { (12.5\%) Surgical treatment and } \\
\text { survival: } 7 \text { (87.5\%) }\end{array}$ \\
\hline
\end{tabular}

CT computed tomography

(Olympus, Tokyo, Japan) in two cases. Although many lesions were observed in the horizontal duodenum, they were visible from the inferior horizontal duodenal angle, which is within the range of the GIF-Q260J. In five cases, the tip attachment was used for upper GI endoscopy, and in some cases, this contributed to the diagnosis. Marking clips were placed in the region of the suspected fistula in four patients, which were very useful in making the definitive diagnosis (Figs. 6 and 10, for case 6).

\section{Discussion}

Amongst the patients diagnosed with ADF during the observation period, only two had shock vitality at the time of visit. However, two of the remaining six patients had shock vitality during endoscopy, and one of them died eventually. It must be recognised that ADF is a disease that causes sudden changes in conditions. However, the patients who could be surgically treated were saved. Prompt and appropriate diagnosis was considered important for improving the survival rate.

Two-thirds of patients with ADF are said to have herald bleeding, transient bleeding before major bleeding $[7,12-15]$, during which, the presentation of the patient mimics normal upper gastrointestinal bleeding. In fact, we presume that the six patients who presented at the hospital without shock vitality in this study were in this state. In order to save the lives of ADF patients, it is important to make a quick appropriate diagnosis during this period of herald bleeding.

In this regard, the history of aortic intervention is important. All of the cases had undergone intervention for the management of aortic pathology. The average time from aortic treatment to the onset of ADF was 53.4 (7-156) months, and the development of ADF was 


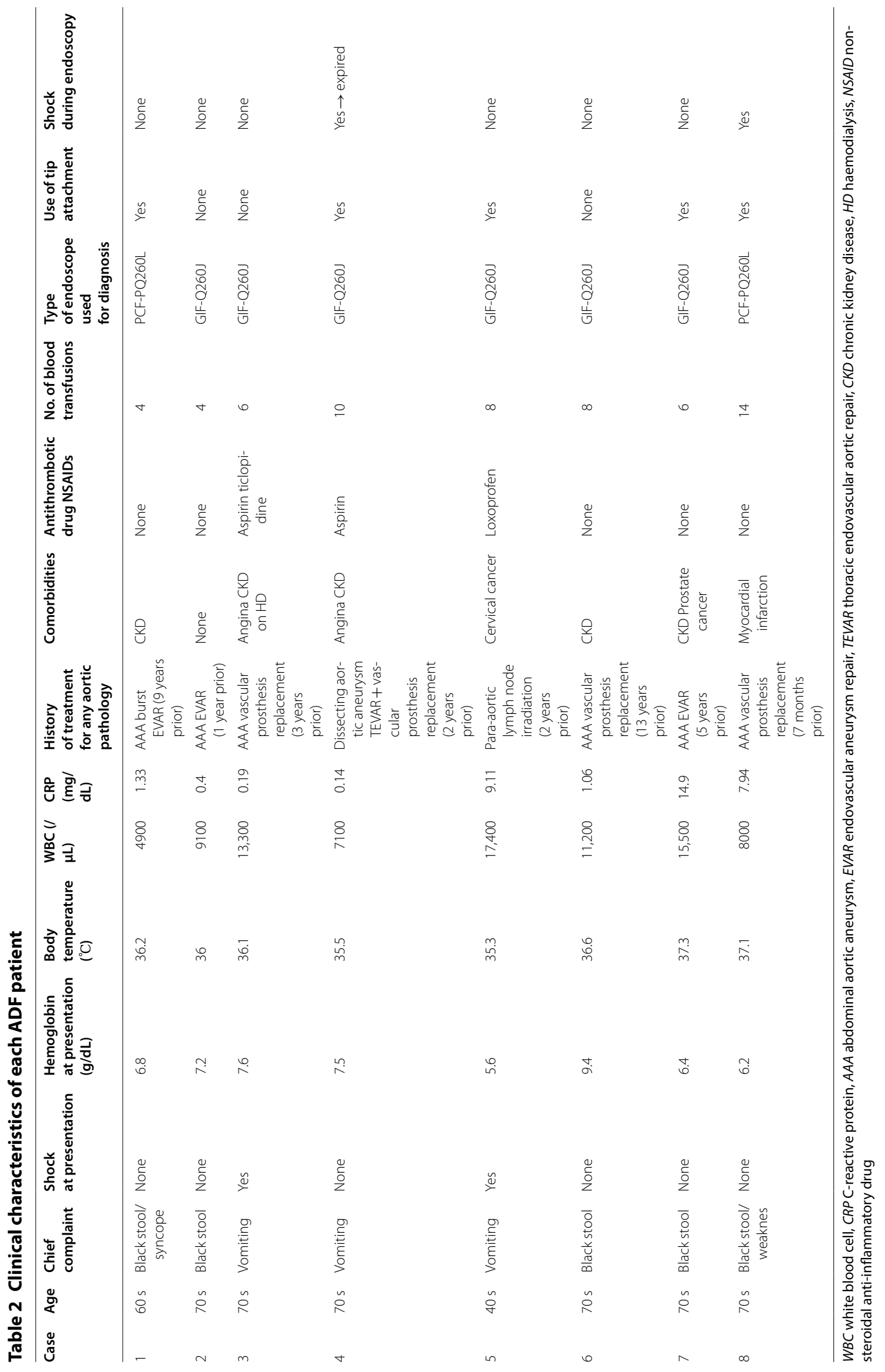


Table 3 Endoscopic/CT findings and treatment in each ADF patient

\begin{tabular}{|c|c|c|c|c|c|c|}
\hline Case & Endoscopic findings & Marking clip & CT Findings & $\begin{array}{l}\text { Fistula } \\
\text { site (part } \\
\text { of duodenum) }\end{array}$ & Treatment & Outcome \\
\hline 1 & $\begin{array}{l}\text { Pulsatile granule-like protuber- } \\
\text { ance of the duodenum }\end{array}$ & + & $\begin{array}{l}\text { The aorta and duodenum were } \\
\text { adjacent } \\
\text { Ectopic air in the aorta }\end{array}$ & $3 r d$ & $\begin{array}{l}\text { Vascular prosthesis replace- } \\
\text { ment } \\
\text { Omental patch closure } \\
\text { Duodenal repair }\end{array}$ & Survived \\
\hline 2 & $\begin{array}{l}\text { Stent exposed into the duo- } \\
\text { denum }\end{array}$ & - & - & 2nd & $\begin{array}{l}\text { Vascular prosthesis replace- } \\
\text { ment } \\
\text { Jejunal patch }\end{array}$ & Survived \\
\hline 3 & $\begin{array}{l}\text { Massive fresh blood of } \\
\text { unknown origin in the } \\
\text { duodenum }\end{array}$ & - & $\begin{array}{l}\text { The aorta and duodenum were } \\
\text { adjacent } \\
\text { Ectopic air in the aorta }\end{array}$ & $3 r d$ & Emergency EVAR & Survived \\
\hline 4 & $\begin{array}{l}\text { Massive fresh blood of } \\
\text { unknown origin in the } \\
\text { duodenum }\end{array}$ & - & $\begin{array}{l}\text { (postmortem imaging) } \\
\text { The aorta and duodenum were } \\
\text { adjacent } \\
\text { A saccular aneurysm of the } \\
\text { aorta adjacent to the duo- } \\
\text { denum }\end{array}$ & $3 r d$ & None & Expired \\
\hline 5 & $\begin{array}{l}\text { Pulsatile lesion with blood clots } \\
\text { in the duodenum }\end{array}$ & + & $\begin{array}{l}\text { The aorta and duodenum were } \\
\text { adjacent } \\
\text { Extravascular leakage from the } \\
\text { aorta to the duodenum }\end{array}$ & $3 r d$ & Emergency EVAR & Survived \\
\hline 6 & $\begin{array}{l}\text { Pulsatile lesion eroding into the } \\
\text { duodenum }\end{array}$ & + & $\begin{array}{l}\text { The aorta and duodenum were } \\
\text { adjacent } \\
\text { A saccular aneurysm of the } \\
\text { aorta adjacent to the duo- } \\
\text { denum }\end{array}$ & $3 r d$ & Emergency EVAR & Survived \\
\hline 7 & $\begin{array}{l}\text { Pulsatile granule-like protuber- } \\
\text { ance of the duodenum }\end{array}$ & + & $\begin{array}{l}\text { The aorta and duodenum were } \\
\text { adjacent } \\
\text { Ectopic air in the aorta }\end{array}$ & $3 r d$ & $\begin{array}{l}\text { Bilateral axillo-femoral bypass } \\
\text { surgery } \\
\text { Laparoscopic removal of } \\
\text { vascular prosthesis }\end{array}$ & Survived \\
\hline 8 & $\begin{array}{l}\text { Massive fresh blood of } \\
\text { unknown origin in the } \\
\text { duodenum }\end{array}$ & - & $\begin{array}{l}\text { The aorta and duodenum were } \\
\text { adjacent }\end{array}$ & $3 r d$ & Emergency EVAR & Survived \\
\hline
\end{tabular}

CT computed tomography, 2nd second portion of duodenum, 3rd third portion of duodenum, EVAR endovascular aneurysm repair

observed in different periods. Patients with upper GI bleeding and a history of intervention in the aorta should be treated considering the possibility of ADF, regardless of prior treatments. In addition, it is said that infection of the aorta may be a risk factor in the development of ADF. In fact, multiple cases with a high WBC count, CRP level, and body temperature were found and were considered to be infected [16].

In a previous study, findings for making a definitive diagnosis of ADF on endoscopy were reported to be exposure of the artificial blood vessels/stents to the duodenal lumen, and the suspected findings included duodenal clots, extravascular pulsatile tumours, and arterial bleeding from an unknown origin. However, these findings are not necessarily observable, and the rate of diagnosis is $13-38 \%$ [3-6]. On the contrary, the pathognomonic finding on $\mathrm{CT}$ was the extravasation of blood from the aorta to the duodenum. However, the diagnostic rate of this modality is $30 \%-61 \%$, which makes it unreliable [4, 8-11]. The findings suspicious for ADF on CT were reported to be loss of continuity of the arterial wall around the duodenum and cystic aneurysm in contact with the aorta/duodenum $[7,8]$. However, a previous study reported delayed diagnosis as the above findings were not observed [2]. In the present study, only one case (12.5\%) was confirmed as ADF by endoscopy or CT alone, which could be considered inadequate as a diagnostic modality. However, when the two tests were combined, a definitive diagnosis was made, and life-saving treatment could be performed.

The following factors might be helpful when performing endoscopy in these cases: (1) using a tip attachment; in some cases, the fistula site may be hidden behind the folds or flexures, which could be detected by using the tip attachment; (2) converting to a long endoscope as ADF is often present in the horizontal part of the duodenum. This is reflected in our results as well as in a previous report [17], where two cases of ADF were diagnosed 


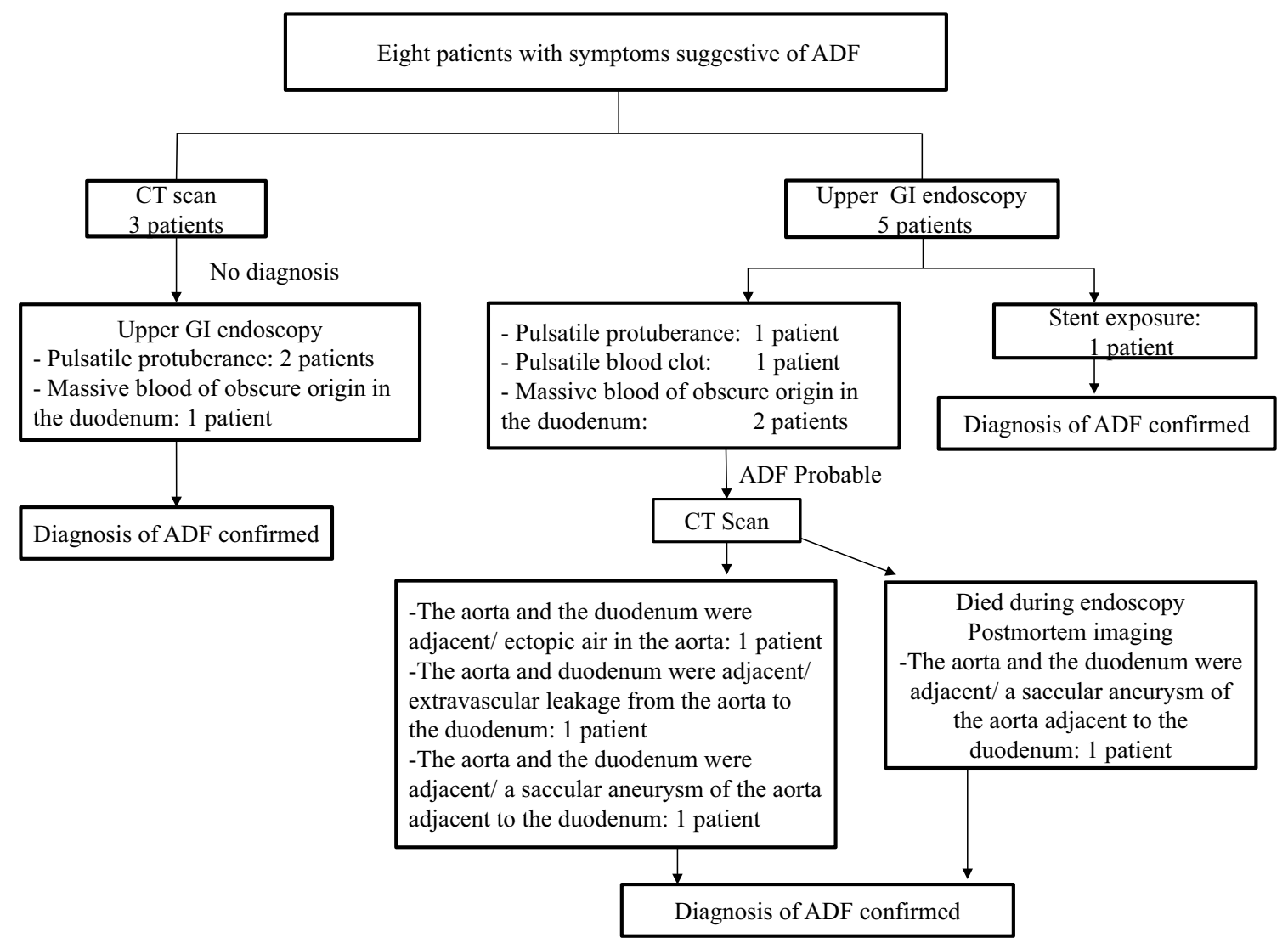

Fig. 1 Flow chart showing diagnosis of aorto-duodenal fistula. ADF Aortoduodenal fistula, CT computed tomography

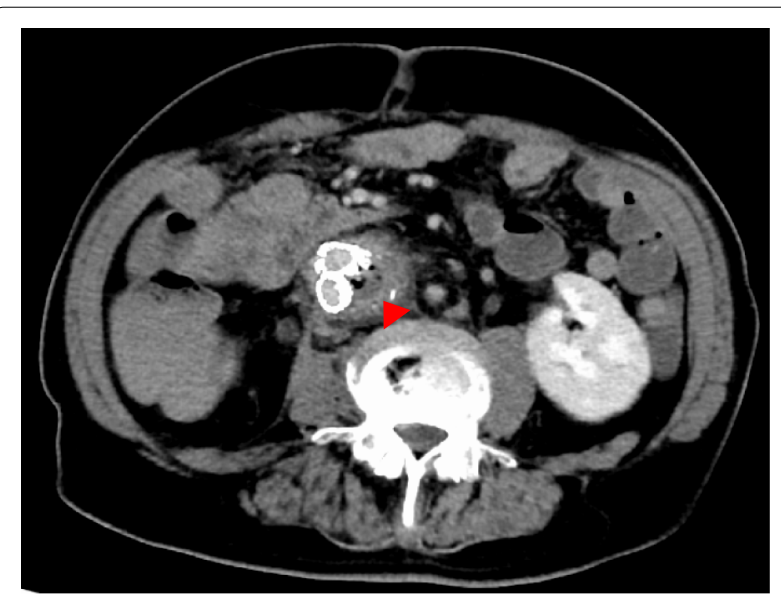

Fig. 2 Contrast computed tomography image after upper endoscopy (case 2). Arrowhead: Image of air in the aorta

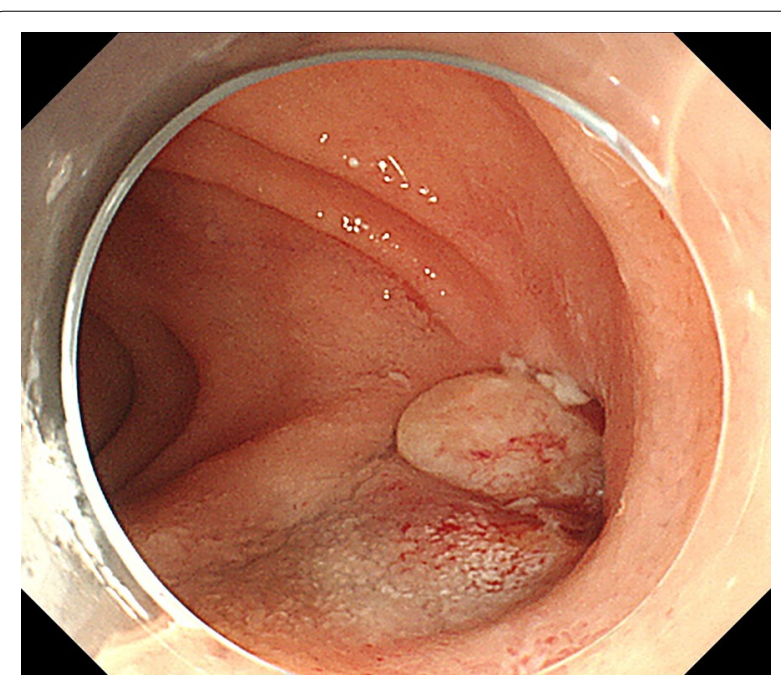

Fig. 3 Upper endoscopy (case 1). A pulsatile, granulation-like protuberance in the 3 rd portion of the duodenum 


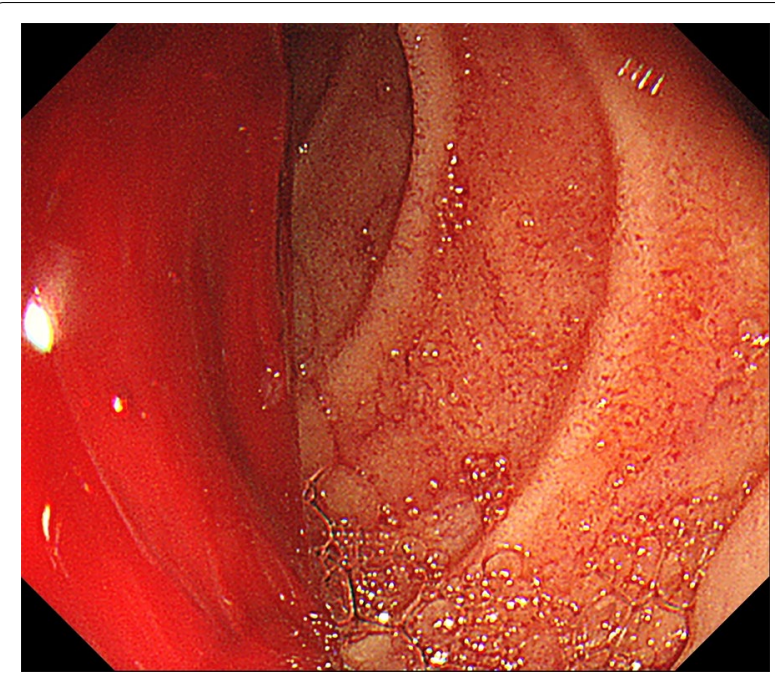

Fig. 4 Upper endoscopy (case 8). Massive fresh bleeding of obscure origin is observed up to the 3 rd portion of the duodenum

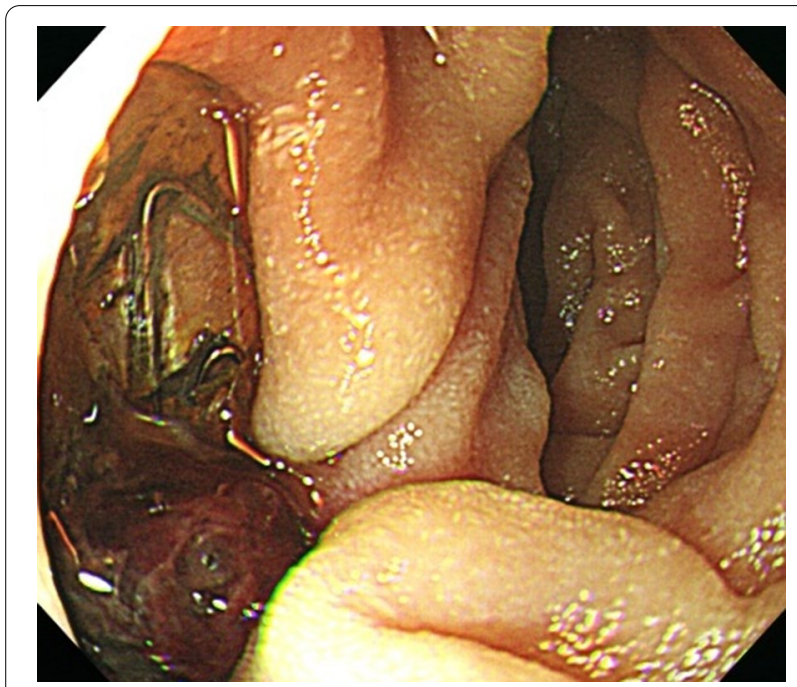

Fig. 5 Upper endoscopy (case 2). Exposure of an aortic stent in the 2nd portion of the duodenum

using a long endoscope and upon observing the deep duodenum; and (3) using marking clips and performing the CT scan after applying the marking clip, which could make diagnosis of ADF easier (Fig. 6, 10, from case 6).

The limitation of this study is that we were unable to confirm the timing from the onset to endoscopy or CT.

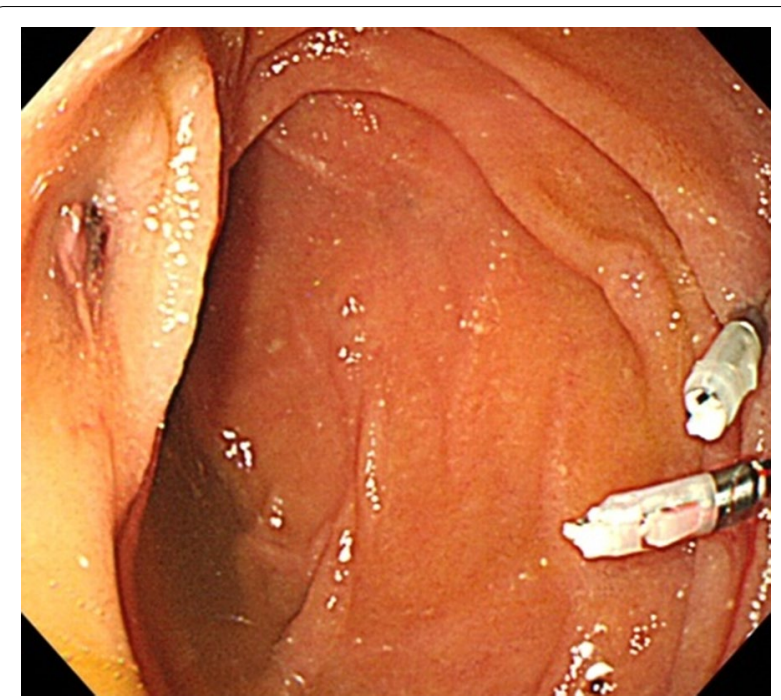

Fig. 6 Upper endoscopy (case 6). Pulsatile erosion in the 3rd portion of the duodenum. A marking clip is placed on the opposite side

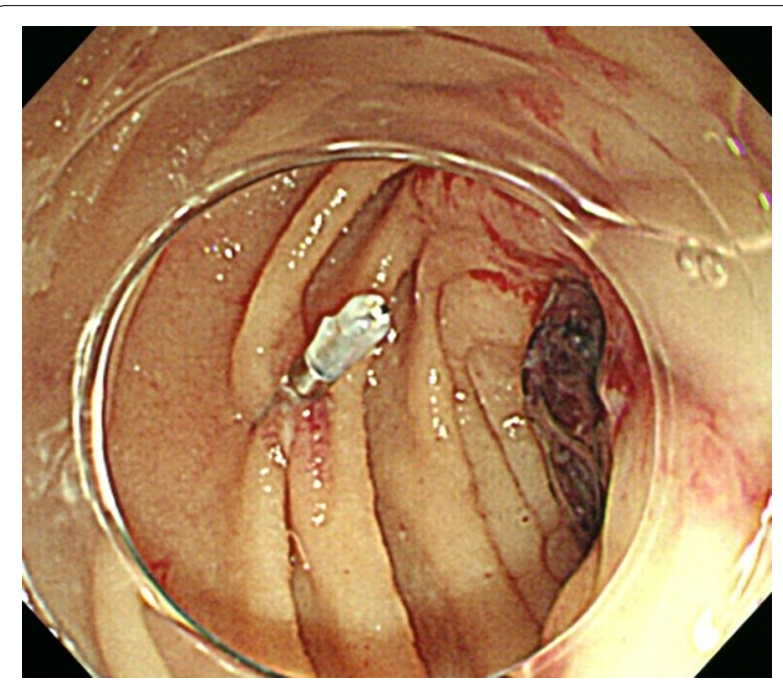

Fig. 7 Upper endoscopy (case 5). Pulsatile blood clot in the 3rd portion of the duodenum. A marking clip is placed on the opposite side

\section{Conclusions}

In a patient presenting with upper gastrointestinal bleeding, a history of intervention involving the aorta should increase the suspicion of ADF. A combination of endoscopy and CT scan is of utmost importance for arriving at a definitive diagnosis. This is especially necessary if there 


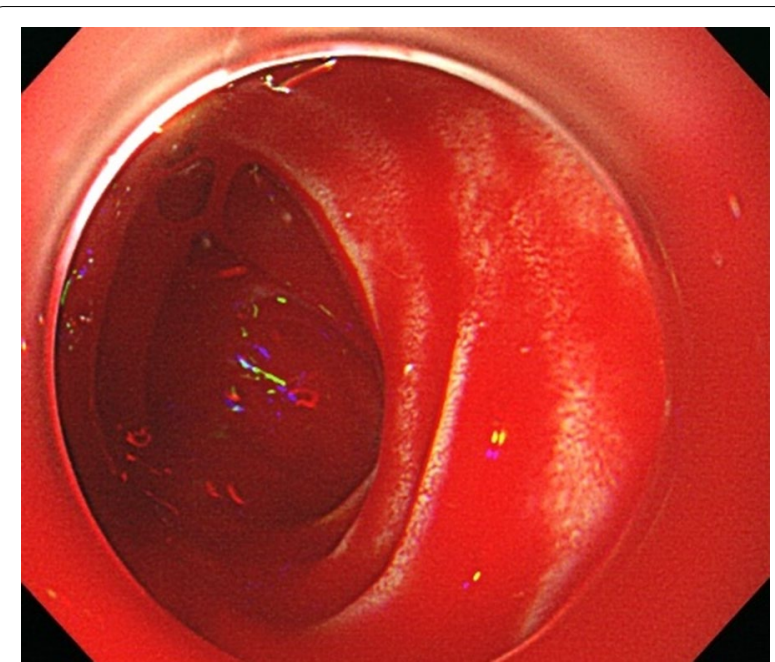

Fig. 8 Upper endoscopy (case 4). Massive fresh bleeding of obscure origin is observed up to the 3 rd portion of the duodenum

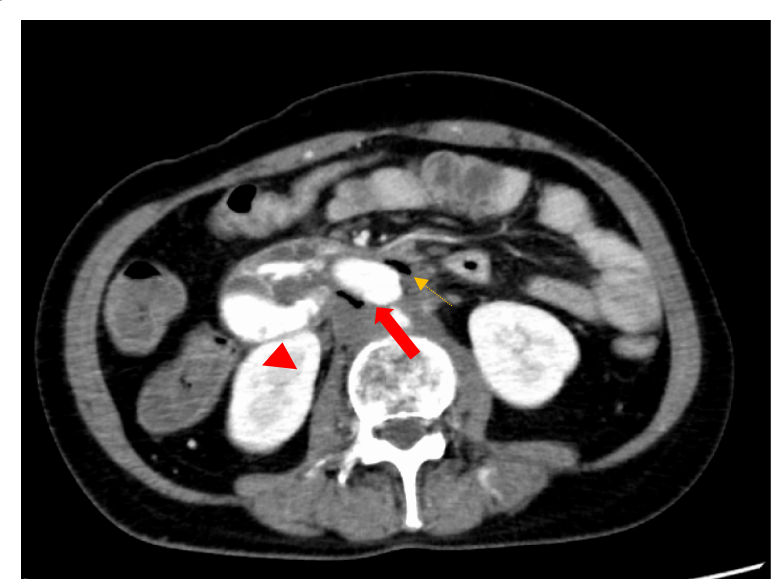

Fig. 9 Contrast computed tomography image after an upper endoscopy (case 5). Arrow (solid red)/arrowhead (red): extravascular leakage from the aorta to the duodenum is observed. Arrow (dotted orange): image of air seen in the aorta

is a chance that infection may complicate the situation. Furthermore, when performing upper GI endoscopy in such patients, tip attachment, converting to a long endoscope, and using a marking clip may aid in the diagnosis.

\section{Abbreviations}

ADF: Aorto-duodenal fistula; AEF: Aorto-enteric fistula; CT: Computed tomography.

\section{Acknowledgements}

We would like to thank Editage (www.editage.com) for English language editing.

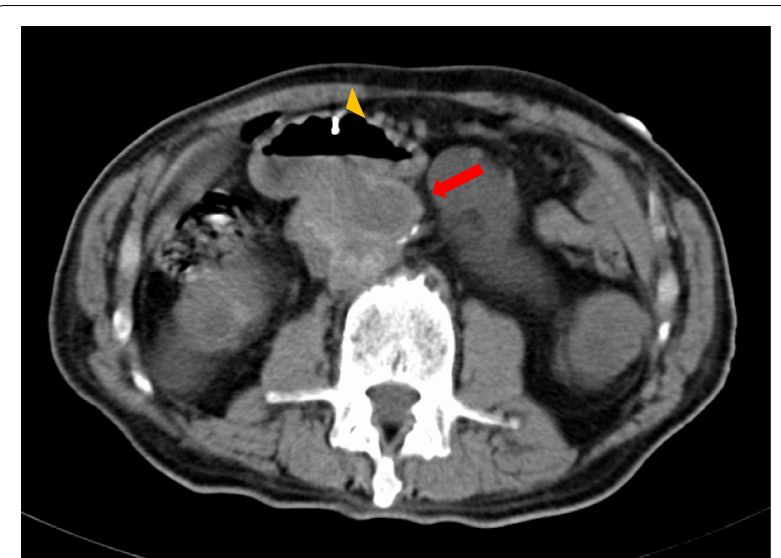

Fig. 10 Simple computed tomography (CT) image after an upper endoscopy (case 6). Arrowhead: a cyst-shaped aneurysm adjacent to the duodenum is seen. Arrowhead: since a marking clip was placed on the opposite side, diagnosis of aorto-duodenal fistula was easy, even with a simple CT

\section{Authors' contributions}

$\mathrm{Cl}$ collected data, performed the analysis, and wrote the manuscript; AS, KK2, MK revised the manuscript; and CS, KK1, TN, JT, SM, and JK contributed equally to this work. All authors read and approved the final manuscript.

\section{Funding}

This study received no funding.

\section{Availability of data and materials}

The datasets used and/or analysed in the current study are available from the corresponding author upon reasonable request.

\section{Ethics approval and consent to participate}

The Institutional Review Board Ethics Committee of the Tokushukai Medical Group approved this study and waived the requirement for informed consent; instead, patients were allowed to opt out of the study.

\section{Consent for publication}

Not applicable.

\section{Competing interests}

The authors declare no conflicts of interest.

\section{Author details}

1 Gastroenterology Medicine Center, Shonankamakura General Hospital, 1370-1 Okamoto, Kamakura, Kanagawa 247-8533, Japan. ${ }^{2}$ Department of Surgery, Shonan Kamakura General Hospital, Kamakura, Kanagawa, Japan.

Received: 25 September 2020 Accepted: 14 January 2021

Published online: 01 February 2021

\section{References}

1. Hirst AE Jr, Affeldt JE. Abdominal aortic aneurysm with rupture into the duodenum. A report of eight cases. Gastroenterology. 1951;17:504-14.

2. Okada A, Yoshimura T, Tatsuta T, Sakuraba H, Hanabata N, Shimoyama T, et al. A case of graft-duodenal fistula 25 years after operation for aortic coarctation. J Jpn Soc Gastroenerol. 2012;109:2049-57.

3. Matsuura N, Fujitani K, Nakatsuka R, Miyazaki S. Secondary aortoduodenal fistula: report of 3 cases. Jpn J Gastroenterol Surg. 2018;51:406-14.

4. Saers SJ, Scheltinga MR. Primary aortoenteric fistula. Br J Surg. 2005;92:143-52. 
5. Delgado J, Jotkowitz AB, Delgado B, Makarov V, Mizrahi S, Szendro G. Primary aortoduodenal fistula: pitfalls and success in the endoscopic diagnosis. Eur J Intern Med. 2005;16:363-5.

6. Brand EJ, Sivak MV Jr, Sullivan BH Jr. Aortoduodenal fistula: endoscopic diagnosis. Dig Dis Sci. 1979;24:940-4.

7. Samukawa K, Aoki J, Ohtsuki Y. Surgical correction of arterio-enteric fistula: report of three case. Jpn Coll Angiol. 2009;49:423-9.

8. Goshtasby P, Henriksen D, Lynnd C, Fielding LP. Recurrent aortoenteric fistula: case report and review. Curr Surg. 2005;62:638-43.

9. Wood A, Bendjelid SM, Bendjelid K. Primary aortoenteric fistula: Should enhanced computed tomography be considered in the diagnostic workup? Anesth Analg. 2005;101:1157-9.

10. Perks FJ, Gillespie I, Patel D. Multidetector computed tomography imaging of aortoenteric fistula. J Comput Assist Tomogr. 2004;28:343-7.

11. Lee JT, Saroyan RM, Belzberg G, Pianim NA, Bongard FS. Primary aortoenteric fistula: computed tomographic diagnosis of an atypical presentation. Ann Vasc Surg. 2001;15:251-4.

12. Capaldo GR, Amin RM. Aortoduodenal fistula. Two case reports and a review of the literature. J Cardiovasc Surg. 1996;37:567-70.
13. Szilagyi DE, Smith RF, DeRusso FJ. Contribution of abdominal aortic aneurysmectomy to prolongation of life. Ann Surg. 1966;164:678-99.

14. Sweeney MS, Gadacz TR. Primary aortoduodenal fistula: manifestation, diagnosis, and treatment. Surgery. 1984;96:492-7.

15. van Olffen TB, Knippenberg LH, van der Viet JA, Lastdrager WB. Primary aortoenteric fistula: report of six new cases. Cardiovasc Surg. 2002;10:551-4.

16. Akimoto K, Nagai A, Sugiyama S, Hamanaka H, Ueyama T. A case of aortoduodenal fistula after Y-type artificial blood vessel replacement that was lifesaving. Surgery. 1987;41:1851-4.

17. Ohira M, Miura Y, Sasaki M, Yamaguchi T, Sakimoto H, Koide K, et al. A case of secondary aortoduodenal fistula developed 6 years after an aortic aneurysm. J J.jpn Soc Gastroenterol Surg. 2004;37(2):153-8.

\section{Publisher's Note}

Springer Nature remains neutral with regard to jurisdictional claims in published maps and institutional affiliations.
Ready to submit your research? Choose BMC and benefit from:

- fast, convenient online submission

- thorough peer review by experienced researchers in your field

- rapid publication on acceptance

- support for research data, including large and complex data types

- gold Open Access which fosters wider collaboration and increased citations

- maximum visibility for your research: over $100 \mathrm{M}$ website views per year

At $\mathrm{BMC}$, research is always in progress.

Learn more biomedcentral.com/submissions 